\title{
Use of Virtual Reality as an Alternative Practical Tool in Higher Education during the Covid-19 Pandemic
}

\author{
Noreen Sarai*1, Dr Loveness Museva ${ }^{2}$ \\ ${ }^{*}$ Computer Science, Midlands State University, Gweru, Zimbabwe \\ ${ }^{2}$ Educational Policy Studies \& Leadership, Midlands State University, Gweru, Zimbabwe
}

\begin{abstract}
This research paper aims to analyse the concept of virtual reality as a practical tool to bridge the gap created by inadequacy of hardware equipment, inability to carry-out physical practical exercises due to the COVID-19 pandemic and expertise to carry out practical work. The research was bounded by the research questions that focused on analysing whether VR systems could be used as alternatives in laboratory work, analysing the impact of using such systems and also identifying the possible challenges likely to be faced alongside their mitigation strategies. The research was based on the philosophy of positivism as the researchers sought to test the possibilities of usage of virtual reality as alternative tools in higher education. The research method used in this study was the mixed method approach as the research employed both qualitative and quantitative data and analysis. The data was obtained through use of questionnaires and checklist and was then analysed statistically. When analysing the impact, an open-software was used by a control group of students who implemented a VR system for research purposes. Students were then evaluated basing on the usage the software. Results were then produced and conclusions drawn on whether VR tools could be used as alternatives in higher learning. Results showed that it is possible to use VR systems as alternatives practical tools in higher learning and showed more of positive impact on the learning process of students. Possible mitigation mechanisms were also established with goal of cabbing the possible challenges likely to be faced when using VR systems. The study recommended the use of VR systems as possible as they were able to enhance retention of knowledge by the students and they were to lighten up the learning space as students show so much interest when learning whilst using them.
\end{abstract}

Key words: Virtual Reality; Simulation; higher learning; COVID-19; practical tool

\section{I.INTRODUCTION}

$\mathrm{T}$ his research focused on the application of Virtual Reality as a practical tool in Higher learning. We considered the case a State University which is an Institute of higher Learning in Zimbabwe offering Engineering and Science programmes. Each academic year students doing the Computer Systems Engineering programme within the Computer Science Department normally have 6 out 12 modules that require usage of hardware components. In most instances these components are not available hence the theory approach is normally taken and sometimes it is left for the student to learn about these components during their internship programme. The COVID-19 pandemic made it worse as face-to-face lessons were limited. Ultimately there is a situation where throughout the whole programme $50 \%$ of the modules being done by the students can be affected negatively.

The Techzim magazine (2015) stated that the Zimbabwean government developed a national ICT policy in 2005 and later revised it in 2015. The policy entails that ICTs should be used more in most organisations for their day to day business but they should respect the issues of confidentiality at a national level. The policy does not get into detail on the actual usage but rather organisation can then develop their own ICT policy that's feeds into the national one.

According to Isaacs (2007), the policy as informed both by a Harvard University-guided e-readiness survey, which suggested the country, was not e-ready. There survey suggested that internationally ICTs are being used more often hence use of VR systems is more common in those countries. Developments have since taken place like the introduction of Education 5.0 and this has seen more inclusion of ICTs in education showing that as a country we are ready for it unlike the conclusion that was drawn in 2005. The ICT policy has since been revised in 2015 and it further stimulates usage of IT equipment and services but is silent on the issue of usage of virtual reality in education sector. According to a report done by Technomag (2017), currently in Zimbabwe there is no higher education institute using this technology among all the seventeen (17) state and private universities in the country. As reported by Techno magazine (2017), a company called Veativa was working with eLearning Solutions (a Zimbabwean company) with goal of introducing virtual reality in the classroom, but since then it is still work in progress. This just showed the need of accessing feasibility of usage of such technologies at higher institutions.

The state university being focused, like any other institution of higher learning was facing challenges in purchasing the much needed hardware equipment for laboratory work done by the students as shown by reports from respective lecturers who taught hardware based modules for the semester August to December 2019. This was also shown in the quarterly departmental reports of July 2019 and November 2019 where 
hardware equipment requests were being requested every now and again and sometimes it's the same request that would not have been fulfilled. As they have cited non availability of these components even from the ITS department. The modules that require such components include Microprocessor systems, Data communications and networking and VR development and programming among others. The institute is mandated to offer science degrees and because of the profound practical aspect therein, there is a problem of resources needed for effective learning. The institute requires tools that can bridge the gap created by inadequacy of resources.

Focus was made on the Computer Science department which consists of programs dealing with Computer systems engineering and Computer science as specified in the departmental regulations. Most of the practical courses that are done in the school are software development or programming practicals. These can be done using software that is normally easier to access and available in the department laboratories.

However, some of the practicals are hardware related and this is the area that requires hardware resources which are not always available as shown by the request from the departmental reports that are presented to the faculty board at the beginning and end of each semester. An example of such practicals is building up a complete computer system from scratch by assembling separate hardware components. The required components may not be easily available. The institute experiences a problem whereby some students graduate without adequate knowledge in those areas which has a negative impact on the image of the institute.

Students within the Computer science department are facing challenges of not conducting all the necessary hardware related practical exercises due to the COVID-19 pandemic as face- to face lessons are being limited and in some instances there is unavailability of physical tools to use. Hence this issue is limiting the much expected knowledge they are supposed to acquire. Some practical modules are conducted theoretically with minimum or no practical elements, such that practical exposure on the students' part in most cases is limited. The inclusion on ICTs in the curriculum of their modules is must as being directed by the university, but in some cases usage and implementation of some basic ICT tools such as laptops, high performance machines is limited. At the end of the day it is vital to try to find out the possibilities of using such ICTs like virtual reality in the lessons of the students.

\section{REVIEW OF RELATED LITERATURE}

Coffta (2017) considered a literature review as a comprehensive summary of previous research on a topic. The purpose of reviewing related literature was to give an understating of the research area and to review the works of other scholars in relation to the research topic. Knowledge gaps were identified in order to justify the undertaking of this study. A funnel approach was taken in analyzing literature where the general concepts and underlying theories were studied then narrowed down to core issues of the research. The review started with defining what virtual reality is and then conducts the review basing on the research questions.

\section{A. What is virtual reality?}

Virtual Reality (VR) is a computer-generated environment in which the user is able to both view and manipulate the contents of that environment. It allows for intuitive, real-time interaction, supported by an intelligent, realistic 3D environment. In an educational context, VR allows the learner to both view and manipulate virtual objects in a manner similar to that of a real environment Lockwood (2004).

\section{B. International Trends on usage of VR systems}

According to Gosett (2020), in United States of America a company called Labster partnered with Google created virtual laboratories that allowed learners to culture microorganisms, track cellular breathing throughout an implementation routine, even conducting an ultrasound exam on a virtually expecting mother. The research was done by the students and researchers as selected by Google. The research was quite successful in that the students managed to conduct the virtual laboratories with ease and results were obtained that aided more use of such systems.In 2018 a group of anthropology students managed to conduct learning through deep focus, studying ancient Egyptian characters that scribbled along a tomb over the Giza Plateau. Some learners were in a Cambridge lecture room while others were in an East China teaching space; with no one anywhere near northern Africa. How was this done? They used VR. Rumii, virtual reality system developed by Seattle based Dog-head (US) was used to achieve this according to Gosett (2020). The learning process was a success regardless of the remote location. The students were able to navigate the tomb of the Giza Plateau without having to be physically at the site.Gosett (2020) carried out a research where a group of students were learning at Harvard University while another group was at Zhejiang University and were working together as avatars in a classroom equipped with Virtual Reality tools. Both classes were using their VR headsets. Everyone had their goggles on, their instructors launched the laboratory and loaded up 2D and 3D models of the Sphinx plus one of the tombs, which the groups could then clutch and roam around in the virtual learning environment. The Kremer Museum, which arranged 72 portraits of the Dutch and Flemish Old Masters in a virtual reality gallery, was launched in late October 2017 in New York. The virtual museum allows visitors to examine the artworks 'surface and colours up close, as well as view the reverse of the paintings to explore each works unique stamps of provenance as specified by Gosett (2020). The museum is downloadable in app stores such as Oculus and Vive. When one has the hardware for the VR one can then tour the museum and learn. 


\section{Regional Trends}

EHL (Ecolehôtelière de Lausa) launched a virtual reality program in South Africa. The Housekeeping Virtual Reality program began with the February 2019 intake. A group of five students worked together with one student wearing the Oculus glasses (HDM), the others could see what he/she was seeing on a display monitor as highlighted by Maseko (2019). Julia Aymonier, Chief Information Officer, EHL Group said that was needed to introduce more gamification and experiencebased learning into the curriculum used by students. This will include inclusion of augmented reality (AR) and mixed reality (MR) technologies. There is need to train professors, teachers, lecturers, trainers and other educators so they can become reluctant to use such tools efficiently. While the future of education is positive, more scientific studies assessing the effectiveness of new methods should be conducted before a decisive conclusion can be drawn concerning the importance of developing such systems in teaching.In 2009, Afriten Technologies a South African company created the first ever Augmented Reality system stall in the country. The stall AR system was used at a nation-wide road show for Volkswagen, when launching the new VW Polo vehicle. It had a 42" LCD kiosk with a high efficient resolution, Sony camera and camera stream. The visitors could hold the page up to the screen showing the new vehicle. They could also tap on the page to change the features of the car such as car rim designs and its colours as illustrated by Afriten Technologies (2019).

\section{Local Trends}

Njerekai (2019) proposed development of an application that uses the concept of virtual reality $360^{\circ}$ to be used in touring world-scale heritage site, the Great Zimbabwe monument. Upon time of publication of article in December 2019 the system was not yet operational. This project informed and educated visitors about the monument and hence increases visitation by tourists. This tourist magnet can be reachable to the physically challenged and those reserved by finance, geographical distance and time as specified by Njerekai( 2019). Njerekai (2019) said to produce such virtual videos it is important for the spherical images of the monument to be shot first with a $360^{\circ}$ camera and then stitched into software to obtain high-resolution images. The virtual tour guide videos can then be uploaded on a server and everyone access them through different gadgets upon payment of a small fee.Singapore based company; Veative was in Zimbabwe in 2017 working with eLearning Solutions in a bid to introduce Virtual Reality into the classroom to aid in teaching and bringing life into education. According to the Technomag (2017) the Veative Director of Products Aditya Hansen said that teachers can control what the students get to see and he or she will be able to monitor how long the students are spending on a particular task and those analytics can help a teacher in making student assessments.Another organisation Phenomenon Technologies worked on creating virtual reality experiences that allows learners to travel and explore various career paths and applied learning experiences at a low cost.
They used Virtual Reality (VR) because it enables the learners to have an immersive presence of the environments presented to them. Through this, students have been given the opportunity to virtually visit locations they never thought physically possible and gain a better appreciation of what they learn as the experiences are in line with their curriculum. 200 schools signed up to be on the platform. In August 2019 however, operations for the platform had to be discontinued due to economic challenges. This was a turning point as more sustainable ways to roll out the service had to be explored as suggested by Masarakufa (2020).

\section{E. Can VR be used as an alternative in education?}

Clark (2006) carried out a research with goal of analysing whether Virtual Reality systems can be used in everyday life and in particular learning. He found out that Virtual Reality systems can be used to force the learning process to be more interesting and fun with the goal of improving motivation and responsiveness, reducing costs when using the goal and the actual environment. VR technologies are likely to assist more in learning in future too as students will be able visualize abstract concepts, observe events at atomic or planetary levels, and also to visit VR environments and interacting with events that geographical distance, time, or safety factor make it impossible.So far in Zimbabwe implementation is less or in other words little is being done. As shown from literature reviewed so far, school trips done using VR, for example a trip to a monumental heritage site at Great Zimbabwe, but it is still work in progress according to the Technomag (2017).In South Africa there are a reasonable number of companies which offer VR services. For example a Virtual Reality Agency based in Johannesburg South Africa has been exploring virtual reality since 1998. They have been developing their own and custom made virtual reality and $360^{\circ}$ video camera systems and software solutions. Therefore learning institutions may opt to use such companies in developing their curriculum into VR.

In developed countries like United States of America and United Kingdom a number of learning institutions have proved that VR can be used as an alternative in education. They are using VR in certain courses and certain subjects though they have better resources for implementing VR learning it has been difficult to incorporate every learning subject in VR than most countries according to Afriten Technologies (2019).

\section{F. Impact of use of VR technologies in Higher Education}

In Zimbabwe there are no notable learning institutions which are using VR in their curriculum. VR in Africa is mainly used for playing games using the PlayStation. African Leadership University which has sites in Mauritius and Rwanda, only uses VR for touring the campus as stated by alueducation.com (2017). However in developed countries like United States of America, at Colorado State University's Department of Biomedical Sciences there is a 2,500-square- 
foot VR lab that can accommodate up to 100 people.It helps neurology and anatomy students to see single-plane images and trying to help them interpret the images in three dimensions. Arizona State University (California) uses the VR to allow remote students to participate in lab exercises in online biological science degree programme. Swansea University (United Kingdom) also use VR in biomedical learning as stated by Gosett (2020) is just few examples where VR learning has been implemented. The impact of using VR in learning is as follows:

Geographical Distance learning - Students are now able to attend lessons regardless of geographical location through use of VR systems. For instance Stanford School of Business is offering a certificate programme which is fully delivered through VR. The ability of watching an online lecture while not being able to attend, is helping break a lot of obstacles in higher education and is a very hopeful field with many more universities joining in, in the near future according to Daily (2018)

Better cooperation between students and teachers. According to Daily (2018), when one thinks of using virtual reality in a classroom, one might probably think that it completely takes away the chance for the instructor to focus on each and every student. In reality though, VR systems actually helps in oneon-one student learning.

Language immersion: Immersion helps in learning a new language and this can be done through use of VR tools. Stenger (2017) highlighted that since most students cannot afford to travel to another country for weeks at a time, virtual immersion can be used to know the languages. One such application is Unimersiv, which can be used alongside the Oculus Rift headset. The application allows students to connect with people worldwide and practise their language skills while interacting with other learners in a virtual world as specified by Stenger (2017).

Philosophical theories can be brought to life through use of virtual reality. The Sevenoaks School in the UK currently is using VR headsets in its philosophy lessons as a way of introducing learners to the French philosopher Rene Descartes' vision argument. Research done by Stenger (2017) specified that a learner commented that it was amazing to think that one could test and understand more about such centuries-old theories using the latest modern technologies.

\section{Architecture and design}

Some schools found out that virtual reality technologies are an excellent way to ignite students' creativity and keep them well engaged, especially when it came to architectural design. For the last few years, David Beach, an assistant professor at the Drury University Hammons School of Architecture, has been researching on ways to apply VR technologies in architecture and has a strong belief that it could open up countless possibilities in architecture and design. The Oculus Rift hardware made it possible for architects to use computer generated 2D/3D models and place viewers into those models with goal of bringing their plans to life. At a school in Ireland, learners had been using VR tools to construct 2D/3D models of historical Irish monuments and then navigate them virtually as specified in a research by Maseko (2019).

Special education- Stenger (2017) indicted that the Jackson School for special needs learners in Victoria, Australia had been also using the Oculus Rift headset. Technology and special education tutor Mathieu Marunczyn explained that the Oculus Rift had helped ignite his students' imagination and gave them visual insight to their lessons.

Game-based learning: Virtual reality technologies are likely to change the way games could be used in learning. Game-based learning increases engagement and motivation, and virtual reality can take this to another higher level. Maseko (2019) indicated that Jane Wilde, an instructor at Marlboro College in Vermont who had been using games in her lessons for some time now, says that virtual reality games made a substantial difference in the classroom. Normally people are judged by their activities and so much can be accomplished in a virtual reality environment that would have been impossible in real life.

Visual learning: A lot of learners are visual learners. VR technologies could be helpful for them with its capabilities of visualisation. Instead of reading about stuff, learners can see the things they are learning about hence making it to visualize complex mechanisms and make them easier to comprehend.

\section{METHODOLOGY}

In this study, the philosophy of positivism was found to be suitable because the researchers sought to test the possibilities of usage of virtual reality as alternative tools in higher education. In addition, positivism will enable the researchers to establish the factors impacting the use of virtual reality in higher education and also the solutions to some of the challenges likely to be faced when using such technologies. Furthermore, the knowledge about factors affecting the use of virtual reality was the objective due to the quantifiable perspective embedded in the philosophy of positivism. This philosophy also ensured that knowledge gained is valid and reliable since the findings of the study are grounded on the data itself rather than the opinions of the researchers. Likewise, the philosophy of positivism does not permit researchers' notions and feelings blur their conclusions. Thus, positivism reduces bias in scientific inquiry since data can be quantified and verified in this study.

The appropriate research method in this study was the mixed method approach as the research employs both qualitative and quantitative data and analysis. Mixed methods, employs the elements of both quantitative and qualitative methods in collecting and analysing data in the same research. In particular, mixed method research makes use of the strengths that are inherent in both quantitative and qualitative research as specified by Patterson ( 2013). Quantitative research 
method focused on quantifying data in order to answer what and how of the study. On the other hand, qualitative research method is concerned with the collection of wide storyline (narrative data) and lived experiences of participants in order to understand the feelings, attitudes and opinions of the participants about the phenomena of interests as suggested by Terrell (2012).

This study used both descriptive and explanatory research designs as proposed by Creswell (2017). The researchers chose a descriptive research design for she intended to describe and illustrate impact of using virtual reality systems and solutions to challenges posed by using virtual reality which is one of its advantages to clearly specify information. This type of design enabled the researchers to report summary data such as measures of central tendency including the mean, mode, deviation, percentage and association among variables.

According to Creswell (2017), a target population is the whole group in which the researchers intends to select the sample for the purpose conducting a scientific inquiry or making observations about a phenomenon. The population for this study constituted of administrative officers involved in academic policy making i.e. the administrators and the Dean, students, teaching staff members and technicians. This population was affected directly and indirectly by use of the VR systems; hence the population was chosen as the students shall use the VR systems, teaching staff members who taught using such technologies whilst administrative members monitored their usage. The researchers had adequate access to work with the population during the research study as she is a member of the university.

Purposive sampling as a non-probabilistic technique was chosen as the sampling technique as focus was on the department that had a greater chance of using the VR systems. A purposive sample is where a researchers selects a sample based on their knowledge about the study and population as defined by Creswell (2017). Participants were selected according to the needs of the study while applicants who did not meet the profile are rejected.

The technique was used to extract the sample as the researchers chose a sample of people who were members of the Computer Science department where the use of the VR system is to be analysed. The sample size included 40 students, 7 teaching staff members, 2 administrative members, faculty Dean and an ICT Technician. Students were selected from level two students doing the Computer Systems engineering programme as they have modules which involve a lot of hardware, teaching staff members and the technician constitute members available within the affected department, Computer Science.

According to Godfred (2016), a research instrument is a measurement dimension that is employed by researchers to gather appropriate data from the study participants. The researchers used questionnaires and checklists as the key research instruments for data collection in the study. The researchers used the checklist during observation of how two laboratory sessions where conducted for Data Communication \& Networking module done by level two within the department. Higgins (2016) defined checklists formats designed to perform repetitive activities to verify a list of requirements or to collect data in an orderly and systematic manner. The main objectives of the checklist were to verify the availability of the learning space, how many sessions were conducted, to observe how the students conduct the session and to survey the issue of availability of hardware components.Furthermore, the questionnaire was suitable for this study because it was cost-effective to collect data from many participants without committing the researchers excessively among participants. The questionnaire for Computer Science department staff members and administrators comprised of four sections. Section A: Demographic data, Section B: Institute Readiness towards ICT technologies, Section C: Attitudes towards use of ICT in education, Section D: Use of Virtual Reality (VR) Systems.The questionnaire for the Computer Science department's students comprised of three sections. Section A: Demographic data, Section B: Attitudes towards use of ICT in education, Section C: Use of Virtual Reality (VR) Systems. The sections and the questions were designed in such a way that data was obtained and helped the researchers to answer the research questions efficiently.The questionnaires' design guides respondents' answers so that they remain focused within the study research questions. The questionnaire comprised of descriptive statements based on a 5-point Likert scale for rating their scores. All questionnaires were delivered directly to the respondents (email and whatsapp) as physical distribution is difficult due to the lockdown in the country. The respondents then returned the questionnaires using the same means.

During the period of this study, the researchers used a laptop for preparing the write-up of the research. The research materials were stored on internal hard drive and external hard drive for back up purposes. Passwords were used as encryption techniques that would help in securing the information.

All data from the questionnaires and checklists was entered in Microsoft Excel version 2010 and afterwards exported to RStudio Statistical Analysis software for descriptive and inferential analysis. The most appropriate descriptive statistics for this study are frequency distributions, mode and interquartile ranges. Data obtained from Likert scale within the questionnaires is ordinal hence mode and IQR are the best statistical analysis options to use as they interpret such data efficiently. Data was presented in Tables in order to show data categories and their variables as well as the descriptive statistics. This made it easier for the researchers to infer research results when interpreting the findings of the data.

Inferential statistics as suggested by Creswell (2017) enabled the researchers to choose whether the patterns observed from the data could be generalised. The following statistical test 
will be performed: Cronbach's Alpha test. Cronbach's Alpha test based on $(\alpha=.0 .70)$ was used to check for internal consistency of the research instruments because of its efficiency.

\section{1) Validity}

Content validity is qualitative measure where the actual content matches the measurement which is a logical method of measurement as suggested by Adhikari (2018). The research instruments used were evaluated in terms of their content validity to verify if the content matches the expected measurement that will produce better results during the research.The content validity of the questionnaires and checklist was be achieved by presenting the research instrument to the supervisor to eliminate questions that do not answer the research objectives and questions of the study. Furthermore, the researchers sought to achieve content validity by designing the questionnaire as suggested by previous studies in technology usage.

\section{2) Reliability}

According to Adhikari (2018) reliability relates to the extent to which a research instrument provides comparable outcomes more than once. To establish the reliability of the research instrument, the researchers used the Cronbach's alpha test to examine the consistency of the respondents' answers to all research constructs as suggested by Bolarinwa ( 2015). A Cronbach's alpha estimate value above 0.70 implies that the research instrument is acceptable while values more than 0.8 are regarded as good and demonstrate high reliability of the research instrument.

\section{A. Ethical Considerations}

The areas evaluated as ethical considerations were the issue of informed consent, confidentiality and anonymity of participants. Informed consent is whereby the participants voluntarily agree to participate in the study after having understood the purpose of the research and its associated risks if any as explained by Boeije (2017). It is regarded a precondition condition in data collection. In this study, the researchers attached informed consent forms to every questionnaire so that the researchers signed before filling the questionnaire.On the other hand, confidentiality is an ethical responsibility which compels researchers to preserve privacy of the participants so that information obtained from the participants is not subject to unauthorised access, disclosure, modification, loss or theft as proposed by Boeije (2017). In this research no names were expected to be provided by the participants when returning the questionnaires so that the information provided remained confidential. The researchers was the only person who received the responses.In order to preserve data privacy, information gained from the participants was password protected and was accessed by the researchers and supervisors only. Furthermore, the data was used for the intention of this study only. Boeije (2017) explains anonymity as a process that entails, that no identifying information is collected from the participants, as well; participants should not be linked to the data. Participants were not allowed to insert their names on the questionnaire.

\section{DATA PRESENTATION, ANALYSIS AND DISCUSSION}

The response rate of the sample size used in research with respect to the information gathering instruments was $94 \%$ as only $6 \%$ of the questionnaires were not returned. Saunders (2015) suggested that the response rate should be at least $90 \%$. This implied that the response rate was acceptable to initiate the analysis and inference of the findings.

\section{A. Demographic distribution of respondents}

Demographics measures used within the study were aimed at discovering the demographic patterns of the respondents to exploit their influence to the research questions.

\section{1) Gender:}

The study comprised of a sample size of fifty-one (51) respondents and the gender distribution statistics indicated that $78 \%$ of the respondents were males while only $22 \%$ were females. The data suggested that there was a slight huge dominance of males over females in the computer systems engineering field given that the respondents were selected using a simple random sampling technique which gave each an equal chance to be selected during data gathering process. Results showed that students dominated the majority of population in the age group 21-29 whilst staff members and administrators are above the age of 29 . The dominance by the age 21-29 showed that there could be a strong chance of acceptance of VR systems as this group usually prefers usage of ICTs in line with the Education 5.0 that strives to encourage industrialisation. This will be achieved through this versatile group regardless of them likely not having much experience and still studying towards obtaining a qualification. This might be counteracted by their desire to explore and learn new technologies.

\section{B. What is Virtual Reality and can it be used as an alternative practical tool in higher learning?}

All participants were asked to provide an opinion in terms of their knowledge of what virtual reality is. Forty respondents, approximately seventy- eight per cent answered that question and most of them were able to provide a reasonable definition though in some cases was not exact. The responses also showed that participants were able to link to ICTs. Some of the responses provided included:

"Virtual Reality refers to use of technology though use of a computer. "(Questionnaire)

"Virtual Reality is a concept that uses simulation. We can only use it through using simulation concepts" (Questionnaire) 
Virtual Reality is an advanced technology that uses simulation and people most like to use. Even I would love to use such systems if given the chance. (Questionnaire)

\section{3) Likert Scale Results -Staff members}

To answer the mentioned research question, focus was on Section B and Section $\mathrm{C}$ of the questionnaire that was constructed for the state university staff. Section B had the theme Institute Readiness towards ICT technologies while Section $\mathrm{C}$ had the theme of Attitudes towards use of ICT in education.

The Likert scale was used to gather information of the respondents' opinion in terms of each factor under consideration for the theme attitudes towards use of ICT. The scale provided five options moving from 1-5 with options strongly disagree, disagree, fair, agree, and strongly agree. Eleven (11) staff members participated in the survey for this section. The results obtained are represented in Table 1. Data was statistically analysed using RStudio Statistical Analysis software. The data was first loaded into the software to test for reliability of data. Cronbach's alpha test was used to examine the consistency of the respondents' answers to the research constructs. Under the theme "Attitudes towards ICT usage" there were seven (7) questions that were loaded against the responses. A value of $\alpha=.0 .791$ was found showing that the data was internally consistent.

\section{TABLE 1 ATTITUDES TOWARDS ICT USAGE -STAFF MEMBERS}

\begin{tabular}{|l|l|l|l|l|l|l|l|l|}
\hline $\begin{array}{l}\text { Ser } \\
\text { ial }\end{array}$ & $\begin{array}{l}\text { Attitudes towards ICT } \\
\text { usage }\end{array}$ & $\mathbf{1}$ & $\mathbf{2}$ & $\mathbf{3}$ & $\mathbf{4}$ & $\mathbf{5}$ & Mode & IQR \\
\hline 1 & $\begin{array}{l}\text { CT improves the quality } \\
\text { of lessons being taught }\end{array}$ & & & & 2 & 9 & 5 & 0 \\
\hline 2 & $\begin{array}{l}\text { ICT improves retention } \\
\text { of knowledge for } \\
\text { students }\end{array}$ & & 3 & & 8 & 5 & 0 \\
\hline 3 & $\begin{array}{l}\text { ICT makes lessons } \\
\text { interesting }\end{array}$ & & 1 & & 10 & 5 & 0 \\
\hline 4 & $\begin{array}{l}\text { Using ICT tools } \\
\text { complicates studies of } \\
\text { students }\end{array}$ & & & 8 & 3 & 4 & 1 \\
\hline 5 & $\begin{array}{l}\text { ICT tools are easy to use } \\
\text { and understand }\end{array}$ & & 5 & 4 & 2 & 3 & 1 \\
\hline 6 & $\begin{array}{l}\text { Lessons are easy to } \\
\text { conduct through use of } \\
\text { ICT }\end{array}$ & & & & 11 & 5 & 0 \\
\hline 7 & $\begin{array}{l}\text { ICT can improve the } \\
\text { image of the institution }\end{array}$ & & & & 11 & 5 & 0 \\
\hline
\end{tabular}

Data from the Likert Scale was ordinal hence the Mode and Interquartile Range (IQR) were tabulated from the results basing on responses in which respondents strongly agree. The mode represented the most popular response for each of the questions 1-7. IQR is a measure of spread as it showed whether the responses are clustered together or scattered across the range of possible responses.

TABLE 2 TABULATION IQR

\begin{tabular}{|c|c|c|}
\hline IQR & & \\
\hline 4 & 5 & 5 \\
\hline 5 & 5 & 5 \\
\hline
\end{tabular}

\begin{tabular}{|l|l|l|}
\hline 5 & 5 & 5 \\
\hline 5 & 5 & \\
\hline
\end{tabular}

Table 2 depicted tabulation for IQR for questions 1 . The responses were divided into 4 quartiles. Q1 was subtracted from Q3 to get the IQR. Process was repeated for all questions. Table 1 showed that most people felt that ICT does improves the quality of lessons being taught as the mode was 5 and also strongly believes that ICT improves retention of knowledge for students.

This showed that higher number of the staff members actually believes in the use of ICT in lessons of the students as the mode was 5 for the majority of the questions. Regardless of them feeling that ICT tools are not easy to understand and somehow complicates the life of students as shown by the results, $100 \%$ of the staff does strongly agree that lessons are easy to conduct using ICT and that it can overall improve the image of the institution.

\section{C. $\quad$ Institute Readiness Theme}

Questions were constructed under Section B that had the theme Institute Readiness towards usage of ICTs technologies, in such a way to gather information in relation to whether VR systems can be used as alternatives in higher learning. The questions included:

1) Does the institute have a policy in relation to use of ICT in teaching?

2) Does teaching staff possess required skills to teach using ICT tools?

3) Do you think that the Computer Science department needs to introduce more usage of ICT concepts?

4) Are students and capable to learn using ICT tools?

5) Does the institute have a policy in relation to use of ICT in teaching?:

\section{Policy Existence}

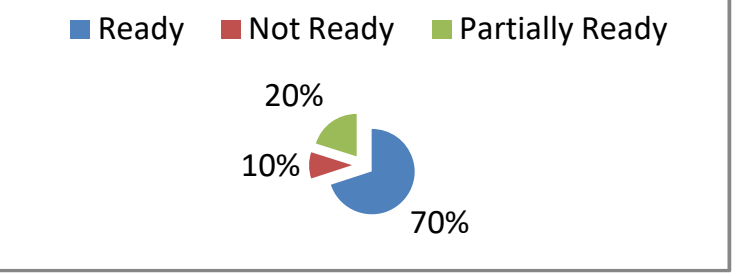

Fig.1: Policy Existence

Fig. 1 showed that $70 \%$ of the respondents were sure that the policy for use of ICT does exist within the institution while $20 \%$ believed that it does not exist and the $10 \%$ of the respondents were somehow not sure.

6) Does teaching staff possess required skills to teach using ICT tools?:

Results showed that $100 \%$ of the respondents' asked agreed that the teaching staff at the university do possess the required skills to teach using ICT tools. Hence this does show that if 
VR systems are to be introduced, the teaching staff can cope with the lessons delivery. This somehow proved that VR systems can also be used as alternative tool.

7) Do you think that the Computer Science department needs to introduce more usage of ICT concepts?

Results obtained showed that $100 \%$ of the respondents felt that it is vital to introduce more usage of ICT concepts within the Computer Science departments. Some reasons cited in the explanations in questionnaires included:

"Introducing more ICT concepts improves the image of the university as a pace setter university"

"Our university is a university in the $21^{\text {st }}$ century hence vital align to technology changes"

"ICT tools are beneficial to the students, university and the country as a whole"

\section{8) Are students capable of learning using ICT tools?:}

Results showed that $70 \%$ of the respondents felt that the students were ready for use of ICT tools. Some reasons provided from the data gathering process were that most students at MSU are driven by technology hence adding more ICT into the lessons would be most welcome. At the same time $20 \%$ felt that majority were partially ready hence requires motivation to brace them for its use whilst $10 \%$ believed that most students were not ready for it.

\section{Use of Virtual Systems}

Section D of the questionnaire for staff members was also constructed with the theme, Use of Virtual Reality (VR) Systems. The goal of this theme was to check whether VR systems can be used as alternative practical tools within the Computer Science department at MSU. Elements that were used to check for this included:

\section{1) Do you know what a Virtual Reality System is?}

The finding showed that $81 \%$ of the respondents have an understanding of what VR systems are. There is a possibility that the $19 \%$ that could not provide an answer to this question are among the administrative staff who normally are not worried about the academic component of lessons.

2) How often practical lessons are conducted for hardware modules and is hardware equipment always available?

This part of the section was only answered by the teaching staff as they are the people who conduct the lessons. $100 \%$ of the staff stated that practical lessons are conducted on a weekly basis for each particular module and that most the time the hardware is rarely available. Eighty-five per cent of the respondents highlighted that there are cases where within the week the practical lessons is not carried due to unavailability of the components. The lack of the hardware showed the essence that VR systems will bring in as they will be able to cover this gap.
3) Do you think the department is ready to use VR as alternative practical tool?

Eighty- eight per cent of the respondents felt that the department is ready for VR usage as they believed that the staff and the students are ready. Some cited that there is need to engage the academic registrar's office and the ITS for smooth introduction of such tools. Whilst on the other $22 \%$ felt that the department is not ready, citing one reason of unavailability of proper funds to introduce such tools. The results showed that with proper planning and engagement with the right offices, introducing VR tools is something that can be done within the department as shown by the results of the questionnaires for both students and staff.

The researchers also constructed another questionnaire that was distributed to 40 students who were part of the sample population. The questionnaire had two themes namely Use of VR systems and Attitudes towards use of ICT tools in education. These themes were used to assess whether VR systems can be used as alternatives tools in learning. Areas that were also addressed in trying to make the assessment included:

\section{1) What a Virtual Reality System is.}

Eighty- six per cent of the respondents were able to provide answers of what VR system is. The definitions provided showed that most students already know what VR systems are. $14 \%$ could not provide sound explanations of what VR systems are. These proved that VR systems can be used as an alternative since the majority of the students already know what it is, hence mostly likely they will be in a position to use them properly.

\section{2) Checking if institution a VR system/platform}

One hundred per cent of the students stated that the institution currently does not have a VR platform as they cited that they have never used one before and if it does exist they are not aware of it. This showed that there was room of introducing such systems.

3) How often do you conduct practical lessons for hardware modules?

As specified by the teaching staff, all 37 students provided information that they do conduct practical lessons weekly. The other three students did not return the questionnaires hence opinion could not be sought. Some went on to explain that for each module they usually have $2 \mathrm{hrs}$ set aside for such sessions per week. They also mentioned that most the time the hardware equipment was not always available and this causing cancellations of such sessions. At times nothing or little to cover up is done. Hence with the current situation introducing VR systems would be vital in order to bridge the gap. 


\section{E. $\quad$ Attitudes towards use of ICT tools in education}

The Likert scale was used to gather information in terms of each factor under consideration for the theme attitudes towards use of ICT in education.

The Likert scale gave five options from 1-5 with options strongly disagree, disagree, fair, agree, and strongly agree. 37 students participated in the survey for this section. The results obtained were represented in Table 3. Data was statistically analysed using RStudio Statistical Analysis software. The data was loaded into the software to test for reliability of data. Cronbach's alpha test was used to examine the consistency of the respondents' answers to the research constructs. Under the theme "Attitudes towards ICT usage" there were five (5) questions that were loaded against the responses. A value of $\alpha=.0 .812$ was found showing that the data was internally consistent.

TABLE 3 ATTITUDE TOWARDS ICT - STUDENTS

\begin{tabular}{|c|c|l|l|l|l|l|l|l|}
\hline $\begin{array}{c}\text { S } \\
\mathbf{e} \\
\mathbf{r i} \\
\mathbf{a} \\
\mathbf{I}\end{array}$ & $\begin{array}{c}\text { Attitudes towards } \\
\text { ICT usage }\end{array}$ & 1 & 2 & 3 & 4 & 5 & $\begin{array}{c}\mathrm{M} \\
\mathrm{o} \\
\mathrm{d}\end{array}$ & $\begin{array}{c}\mathrm{I} \\
\mathrm{Q} \\
\mathrm{R}\end{array}$ \\
\hline 1 & $\begin{array}{c}\text { ICT improves the } \\
\text { quality of lessons } \\
\text { being taught }\end{array}$ & & & 3 & 4 & 30 & 5 & 0 \\
\hline 2 & $\begin{array}{c}\text { ICT helps for better } \\
\text { retention of } \\
\text { knowledge }\end{array}$ & & & 3 & 8 & 26 & 5 & 0 \\
\hline 3 & $\begin{array}{c}\text { ICT makes lessons } \\
\text { interesting }\end{array}$ & & & & & 37 & 5 & 0 \\
\hline 4 & $\begin{array}{c}\text { Using ICT tools } \\
\text { complicates studies }\end{array}$ & 25 & 10 & 2 & & & 1 & 1 \\
\hline 5 & $\begin{array}{c}\text { ICT tools are easy to } \\
\text { use and understand }\end{array}$ & & & 10 & 12 & 15 & 5 & 2 \\
\hline
\end{tabular}

Data from the Likert Scale was ordinal hence the Mode and Interquartile Range (IQR) were tabulated from the results basing on responses in which respondents strongly agree. The mode represented the response given by most respondents for each of the questions 1-5. IQR is a measure of spread, as it showed whether the responses are clustered together or scattered across the range of possible responses.

TABLE 4 IQR TABULATION
\begin{tabular}{|c|c|c|c|c|c|c|c|c|c|}
\hline IQR & \multicolumn{1}{|c|}{} \\
\hline 3 & 3 & 3 & 3 & 3 & 3 & 3 & 3 & 3 & 3 \\
\hline 4 & 4 & 4 & 4 & 4 & 4 & 4 & 4 & & 4 \\
\hline 4 & 4 & 4 & 5 & 5 & 5 & 5 & 5 & & 5 \\
\hline 5 & 5 & 5 & 5 & 5 & 5 & 5 & 5 & & 5 \\
\hline
\end{tabular}

Table 4 showed the tabulation for IQR for Question 5. The responses were divided into 4 quartiles. Q1 was subtracted from Q3 to get the IQR. Process was repeated for all questions.
Table 3 showed that mode of the students believes that ICT does improve the quality of lessons taught and that it does help for better retention of knowledge as shown by the mode of 5. All 37 students stated that ICT does make the lessons interesting. Most students strongly disagreed that using ICT tools does complicates their studies whilst on slightly more students thought that ICTs are easy to use and understand.The results for this question was distributed as shown by the IQR value of 2 which was slightly high, showing that the students had mixed feelings toward the easiness of using ICT tools.

\section{F. $\quad$ How does use of Virtual Reality impact learning in higher education?}

In order to analyse the impact of using Virtual reality in higher education the researchers decided to split the thirty two students in two groups of sixteen each. Eight students were unable to conduct the practical due to unavailability of components and laptop to use as the session was conducted remotely due to COVID-19. The two groups were given work to do, which involving building a complete Personal Computer (PC). This is usually the introductory practical lesson in Computer Architecture module within the department. The first group conducted this practical session using an open source VR system called PC Building Simulator and the other group without use of a VR system. When the sessions were taking place the students were being assessed basing on the following variables:

- Performance - Determining whether all students managed to complete assembling of components successfully within the prescribed session time. Ability to connect the components was also tested.

- $\quad$ Retaining of Concepts - Students were asked to provide a briefly explanation of how we assemble a PC to assess on aspect of retaining the concepts.

- Enthusiasm - Observation was made to find out which students were enthusiastic in their work as this help in better understanding and have minimum distractions.

- Distance Learning - Students were able to carry out their practical session in different remote areas.

\section{G. Performance}

The results from this are shown in Fig.2.

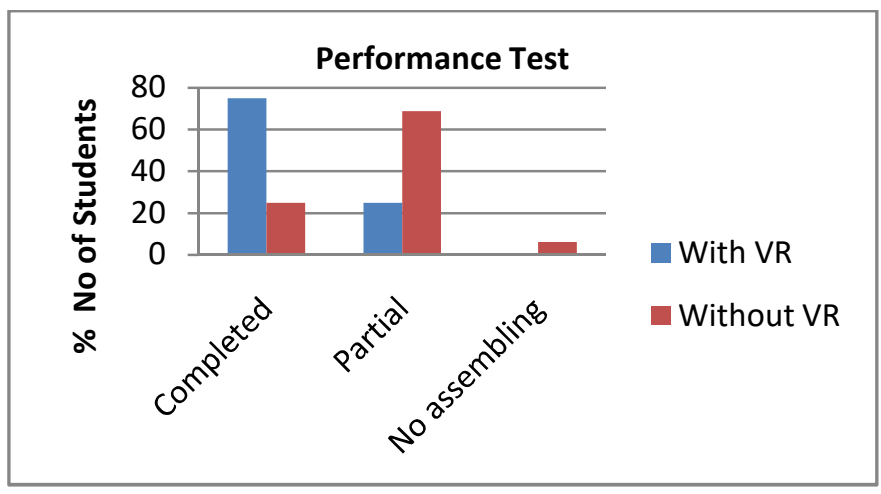

Fig.2 Performance Test 
Fig. 2 showed that $75 \%$ of the students who were using VR system for assembling managed to assemble all components whilst $25 \%$ of those not using VR systems managed to complete the assembling within the practical session. The data showed it is possible to completely assemble the hardware components within the specified lesson time when using a VR system.

\section{H. Retaining of Concepts}

Results after students were asked to explain briefly the assembling of hardware components for an exercise are as shown in Fig.3:

\section{Retaining of Concepts}

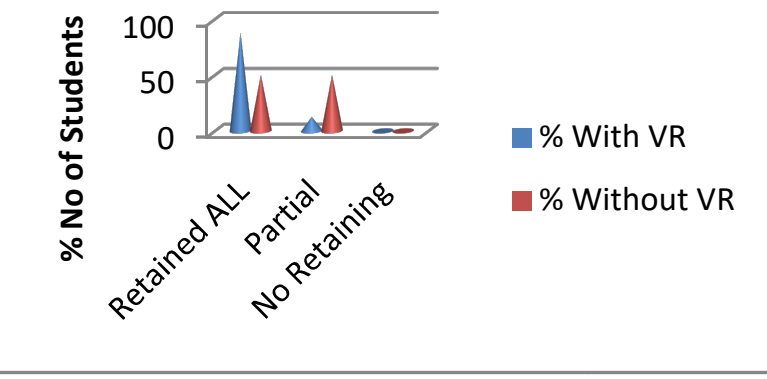

Fig.3: Retaining of Concepts

Fig. 3 showed that all students from both groups managed to retain a particular concept as all of them managed to summarise one or two things about the assembling process for the practical session. This meant that whether a VR system is used or not learning takes place.

\section{Enthusiasm}

From the observation done all students who were using the VR system seemed enthusiastic as shown by their behaviour. After the practical session the facilitator summarised the key points and some students cited their opinion in terms of the lesson. The enthusiasm was then confirmed by the statements made by the students after the session with one student saying:

\section{"I enjoyed it a lot. We need to do it more often".}

Students who were not using it found it being a very tiresome activity. As some were saying:

\section{“The practical session was tiresome, Uuum not enjoyable”.}

Normally when students become less enthusiastic about a certain activity or module this will impact negatively on performance too.

Distance learning - Due to the COVID-19 pandemic the sessions for the test where conducted when students were located in different parts of the country. The best thing about virtual reality systems is that they can truly help everyone to attend a class, no matter the area of location.

\section{J. $\quad$ Checklist Findings}

A checklist was used with goal of verifying the availability of learning equipment required when laboratory sessions are being conducted. The researchers observed a practical session for the module Data Communications and Networking while students were learning the topic "Networking architectures". This session involved a practical session. Results from the checklist are presented in Table 5:

TABLE 5 CHECKLIST RESULTS

\begin{tabular}{|c|c|c|}
\hline Item & Available & Notes \\
\hline Learning Space & Yes & Computer Laboratory \\
\hline Computers & Yes & 66 Desktop Computers \\
\hline Desks & Yes & \\
\hline Chairs & Yes & \\
\hline $\begin{array}{l}\text { Hardware } \\
\text { Equipment }\end{array}$ & $\begin{array}{c}\text { Some available } \\
\text { Computers, Desktop } \\
\text { Fan, Network Cables, } \\
\text { Connectors. }\end{array}$ & $\begin{array}{c}\text { Some hardware } \\
\text { components required for } \\
\text { the sessions were not } \\
\text { available. These included } \\
\text { routers and switches. }\end{array}$ \\
\hline Software & Yes & $\begin{array}{c}\text { Object oriented } \\
\text { Programming software } \\
\text { was available, Artificial } \\
\text { intelligence programming } \\
\text { software tools were } \\
\text { available } \\
\end{array}$ \\
\hline Laboratory Manual & Yes & $\begin{array}{c}\text { Uploaded on the } \\
\text { eLearning }\end{array}$ \\
\hline VR System & No & \\
\hline
\end{tabular}

\section{K. How can we address challenges faced when using}

Virtual Reality?

To answer this research question the researchers used questionnaires and observation data gathering techniques with goal of getting information about the challenges likely to be face when using VR systems. When the challenges were identified, direct of focus was now on determining the likely mitigation strategies for such challenges.

Under the theme Use of VR systems students were asked the following the questions that aimed at finding out their views in terms of the challenges:

- What challenges are you facing now which you feel will be resolved by the introduction VR to the institution?

- Do you think the department is ready to use VR as alternative practical tool?

- Which elements do you feel should not be missing in the VR systems if it were to be implemented?

Under the theme Institute Readiness towards ICT technologies the following questions were posed:

- What are the challenges being faced by the institutions in relation to ICT usage?

- What do you think can be done to solve these challenges? 
The researchers conducted an observation on the control group of twenty (20) that managed to use the VR system, PC Building Simulator for testing purposes. An observation was done when the students were conducting their practical lessons. During the observation students were monitored with aim of trying to identify the challenges if any they faced when using such a system.

Qualitative analysis was performed on the information gathered as key words and phrases mentioned in the short narrative explanations were recorded. After an intensive qualitative analysis of questionnaires and observation during the study, the following challenges were identified basing on the questionnaire responses and the observation:

i. It took time to grasp guidelines on how to use a VR system as shown by the time taken by fifteen (15) of the students. This meant that $75 \%$ needed about 15 minutes to grasp the concepts prior to lesson.

ii. Unavailability of funds to set up a virtual reality laboratory especially when there is need of HMD. Two of the administrators mentioned that the university like all organisations are facing challenges due to the economic situation in the country.

iii. Using VR can be interesting such that students tend to lose focus in the classroom. All the twenty students who used the PC Building Simulator were so excited and some guideline shad to be repeated.

iv. Virtual reality systems needed to be compatible with their users hence there this presents a challenge for audio localization to obtain realistic auditory environment.

v. Depending with the system, ensuring that users are safe is important hence challenges might arise as there is need of VR systems that avoid distress, injury or even harm and cyber sickness.

vi. Use of VR systems requires skilled staff to assist students as shown during the test; the facilitator had to know how the system works in order to assist students properly.

vii. Addressing technical aspects of the VR system can be a challenge, as students were worried about the picture quality, sound and availability of hints when using the system as thirty-five of the student population cited this and this was approximately ninety-five percentage.

\section{RESULTS DISCUSSION}

The results obtained showed an ascendancy of males over females in the field. This was supported by Behrisch, (2016) who specified that proper sampling involves predefining a procedure which is used by researchers to decide on who should participate in the study so that the results of the study can be fairly generalised.

Results showed that students dominate the majority of population in the age group 21-29 whilst staff members and administrators are above the age of 29 . This might increase the level of acceptance of such concepts as Virtual systems as most people who tend to below 49 years tend to appreciate ICTs more as proposed by Terry (2018).

The results were also discussed according to the research questions as follows:

A. What is Virtual Reality and can it be used as an alternative practical tool in higher learning?:

Participants used in the research study were able to define what virtual reality was as some had a vague idea about the concept and some could provide a more detailed definition as shown by some responses provided by them. All the responses showed that they had an idea that VR systems are related to ICTs technologies. This coincided with a research done by Gosett (2020) where most participants who were able to use the VR systems has a strong view point of them and could be able to define what they are. Hence results obtained showed that VR systems could be used as alternatives as minimum training prior to their usage is required and hence less time is likely to be spending on issues to deal with awareness.

The low Interquartile ranges (IQR) values of 0 and 1 represented in Table 1 indicated a sign of consensus, meaning most respondents share the same opinion. This showed that they do agree that it's something that can be implemented in students of higher learning lessons. The results also showed that staff members had a positive attitude towards use of ICT hence it is possible to use of VR systems as an alternative practical tool. Gosett (2020) suggested that most people enjoy using technology. The results obtained tallied with his sentiments. Though the results went a step further in showing that most people feel that use of VR system did not complicate their work, which adds as a unique element of the results.

Seventy per cent of the population could explain in detail the contents of the policy regardless of being sure that it does exist. Most likely this included the Dean and the administrators as they are normally familiar with the policies. With the results obtained it was difficult to conclude if the use of VR tools does exist or need to be embedded within the policy as respondents could not provide more details.

The responses obtained when respondents were asked on the readiness of the institute to introduce ICTs, showed that the institute was ready for more introduction of these ICT tools such as VR systems hence if introduced the teaching staff were ready to accept the change. $21^{\text {st }}$ century education requires more use of ICT technologies as stated by Gosett (2020) and most the respondents thought the same from their response which they provided.

It was found that there was a higher percentage of people who believed that the students were ready for use of ICTs and this showed that using VR as alternative is a possibility.

In a research done by Masarakufa (2020), 200 schools were ready to participate in a programme that would see 
introduction on Virtual systems in Zimbabwe, showing the readiness that existed in people in our Country. This had also been shown by the results of this research.

Results of IQR showed that for questions 1-4 asked the IQR values were low i.e. 0 and 1 indicating consensus among the students. In conclusion the results showed that students do have a positive attitude towards ICT usage, hence proving that VR systems as part of ICT tools can indeed be used as alternatives tools in learning. This was also affirmed by Masarakufa (2020) who mentioned about an organisation called Phenomenon Technologies that was working on creating virtual reality experiences that allowed learners to travel and explore various career paths and applied learning experiences at a low cost in Zimbabwe. When the idea was proposed 200 schools enrolled for the programme showing signs of positive attitude towards use of ICTs.

\section{B. How does use of Virtual Reality impact learning in higher education?}

Results proved that there was a better performance by students who used the VR system. The group that was using the VR system cited combining was a bit easier due to the components being at one place hence it waseasier to assemble quickly. This showed positive impact on the students' part. The results obtained showed that the performance of students increased if they use VR. Stenger (2017) suggested that Virtual reality applications permitted students to attach with individuals from all over the ecosphere and perform their linguistic skills while playing and networking with other learners in a virtual realm, hence improving their learning capability. The results basing on the performance test showed that this is true. Hence VR system do indeed have a positive impact when used in higher learning and less of negative impact as the performance rate was higher when the VR system was used. The better performance implied a positive impact on the lecturers and administrators part as there work tends to be easier. For instance in cases of the administrator's results processing could be a much easier task unlike a situation where there are lots of failures.

Results in Fig. 3 showed that $88 \%$ of the students who used VR systems managed to articulate all procedures in comparison to $50 \%$ of the students who were not using a VR system. This shows that student tend to retain more if a VR system is used for the practical session in relation to a situation where none is used. Those students who used the VR cited that the lesson was interesting; hence this might had contributed to them paying more attention to every detail as explained by Stenger (2017) who also found that students tend to grasp more when they used VR systems. The process of grasping required students to be more attended and required time; hence this showed a negative impact in terms of VR usage for both the students and lecturer. Hence the results correlate as the students showed signs of being skilful hence retain more knowledge when using VR systems.
Students who used a VR system when the impact was being tested showed a lot of enthusiasm. This might also explain why there was a better performance among students who were using VR systems.

This aligned with suggestion made by Clark (2006) that Virtual Reality can be used to brand the learning extra stimulating and entertaining with the resolution of improving the inspiration and thoughtfulness, lessening costs when using the unbiased and the actual environment.

Use of VR systems aided possibility of effective distance learning. According to Daily (2018) being able to watch a lecture on the web while not being physically present, is already helping break a lot of obstacles in schooling and is a very encouraging field with many more universities and schools linking in, in the future. His notions were proved to true as the session was a success.

Table 5 showed that the students had a learning area to use for their practical lesson. The session was being conducted with minimum physical hardware components in the laboratory but more of computers which were working well. There were 66 working computer systems in the laboratory. There was adequate space on the desks were available for students to conduct their work.

The computer laboratory was used as a classroom at the same time as a laboratory. Lack of such adequate components might also reduce the enthusiasm within the students. The fully working computers can be used for VR technology as roughly the numbers of working computers in the laboratory are adequate for students undertaking one particular module at one time.

The researchers concluded that students seemed eager to learn within the learning space as shown by their behaviour and this was a great sign in terms of the learning processing. This showed a positive impact in terms of usage of VR systems as agreed by Gosett (2020) who specified in research that most students tend to enjoy practical work hence VR systems could indeed become useful.

\section{How can we address challenges faced when using Virtual Reality?}

Possible ways of solving the challenges that were obtained during the study were also determined. Some of the ways were suggested by some respondents during the research study. The following strategies were discovered:

i. It was noted that it was necessary for the lecturer to provide time for grasping concepts before session begins hence the lesson plans should constructed to show this. Findings showed that even for a practical session to be done with physical components available, time was also required as stated by Gosett (2020). 
He mentioned that for effective practical lessons to be conducted, preparation is vital to be given to both the students and respective facilitators.

ii. To address the issue of funds, usage of open source VR systems can be used and then customise them to suit the department's curriculum. Funds will be saved to purchase other key hardware components as pointed out by Dede (2016) who said that if an organisation could really sit down and come up with plans that will see proper implementation of VR systems with aim of saving costs.

iii. The respondents specifically the lecturers and administrators specified that regular use of the VR systems can somehow reduce too much excitement on part of the students. Strict monitoring is required to make sure that the students are always focused as also specified by Maseko (2019) in his study where participants had to be monitored when they were conducting a vital research tour.

iv. The results showed that before implementing the VR system, it is vital to first have an understanding of the needs of the students in line with the curriculum, so that suitable virtual environment will be compatible with the users hence training of staff members on usage of VR systems is key for their successful implementation. This was also in line with a research done by Gosett (2020) where he found out that training of participants was the key for efficient use of VR systems.

v. Both students and lecturers specified that safety guidelines and measures are supposed to be in place within the laboratory and the guidelines should be known by the students. There was need to have selection of safe systems to be used during the sessions. Thus whenever someone is using the VR, there must be someone guiding the user and ready to catch him/her when the user fall as also agreed by Dede (2016) who also mentioned this in his research.

vi. The institution's programmers should tailor-make the software according to the module outline and syllabus. The VR developer needs to ensure existence or as close to existence as possible, to allow the spectator to sense like they're there, in the ecosphere of the story. This helps students not to worry much about the technical aspects of the VR system. Maseko (2019) suggested in his research that it is vital for content developers to design VR systems that can easily be used by the students, and should be in line with the required syllabus. His suggestions are in line with the possible solutions to challenges being faced when using VR systems; hence if the mitigation strategies are properly in place, there is a high chance of smooth implementation of such systems.

\section{CONCLUSION}

Findings from the research showed that VR systems can be used as an alternative tool in learning as students, staff and the policy makers were in agreement in terms of introducing such technologies. The target population that was used during the research showed signs of positive attitude toward use of ICTs; hence there is a higher chance of accepting the use of VR systems.VR systems could be used to conduct laboratory lessons and better results are likely to be produced unlike a situation where learners are not using them. The research also concluded that use of VR in higher learning had a more positive impact that negative impact on the learning process of students. The findings also supported this notion as it was shown that use of VR improves performance rate of students. Some VR systems come with additional tutorials and hints and this helps students to understand better and quicker. Use of VR seemed to help students to participate better in the lessons hence becoming more enthusiastic in their studies. Once students become enthusiastic little guidance will be required in their lessons. Results also showed that students tend to retain more knowledge when VR is used as a tool during their lessons. This was also another desirable impact of use of VR systems.Possible solutions to some major challenges were determined during the research study. Some of the solutions include the use of open source VR systems to minimize costs of using VR systems. Other funds could then be used for other critical hardware. Training of students and staff was fund to be necessary to ensure proper and efficient use of VR tools. This also acted as a safety and precautionary measure. It was found to be important to first have an understanding of the needs of the students in line with the curriculum, so that suitable virtual environment will be compatible with the users.

\section{FUTURE WORK}

This study could be extended to all universities in Zimbabwe to get more insight on the status of all higher learning centres. This research study involved use of an open source VR system, further research can be done to find out the results if a customised VR systems that provides 3D visuals is used by the control group. Further research could also be done in analysing the design frameworks of VR systems with the goal of customising them to suit the curriculum of modules within the Computer Science department at the state university.

\section{ACKNOWLEDGEMENTS}

A special thanks goes to the researchers for their dedication towards the research that aided in producing a good research paper. Support from the respective department is worth mentioning as they played a pivotal role during the research study.

\section{REFERENCES}

[1] Adhikari, S.(2018).17 Differences between validity and reliability, Epidemiology

[2] AfritenTechnologies (2019).Augmented Reality Application Development South Africa, www.afriten.co.za 
[3] Behrisch, Lars(2016). "Statistics and Politics in the 18th Century." Historical

Research/HistorischeSozialforschung (2016): 238-257.

[4] Castranova, E. (2007). Exodus to the Virtual World: How online fun is changing reality. New York: Palgrave Macmillan.

[5] Clark, Donald. (2006). Motivation in e-learning. Disponívelem: http://www.epic.co.uk, Março, 2012.

[6] Coffta, M. (2017). Literature Review, Harvey Andruss Library

[7] Cohen, J. (2003). Applied multiple regression/correlation analysis for the behavioural sciences. London, England: Lawrence Erlbaum.

[8] Creswell, J. D. (2017).Research Design Qualitative, Quantitative and Mixed Methods Approaches. Sage, Los Angeles.

[9] Daily, J. (2018). 5 Ways Virtual Reality is Contributing to Education, Veer VR Blog

[10] Dang,Y. (2015). Evaluation of the Use and Usefulness of the digital Library: Case Study Andersonian Library University of Strathclyde United Kingdom.

[11] Dede, C. (2016). The evolution of constructivist learning environments: Immersion in distributed, virtual worlds. Educational Technology, 35(5), 46-52.

[12] Godfred, Y. (2016). Research instruments for data collection, KNUST

[13] Gosett, S. (2020). Virtual Reality In Education: An Overview, Builtin

[14] Isaacs, S. (2007). ICT in education in Zimbabwe: Survey of ICT and Education in Africa. Zimbabwe Country Report. Retrieved from http//:www.infodev.org

[15] Kivunja, C.,\& Kuyini, A.B. (2017). Understanding and Applying Research Paradigms in Educational Contexts, International Journal of Higher Education, v6 n5 p26-41 2017
[16] Lockwood ,D. ( 2004).Evaluation of virtual reality in Africa: An educational perspective. United Nations Educational, Scientific and Cultural Organization

[17] Masarakufa,C. (2020).Phenomenon Technologies: Championing The Use Of Virtual Reality In Local Education. www.webzim.co.zw

[18] Maseko, F. (2019). Virtual Reality in education: Welcome to the new age of learning. news@itnewsafrica.com

[19] Njerekai, C. (2019).An application of the virtual reality $360^{\circ}$ concept to the Great Zimbabwe monument. Journal of Heritage Tourism.

[20] Nowell, Lorelli, \& Norris, Jill, \&White, Deborah \&Moules, Nancy (2017). Thematic analysis: Striving to meet the trustworthiness criteria. International Journal of Qualitative Methods, 16

[21] Saunders, M. (2015). Research Methods for Business Students. Pearson, New York.

[22] Seipel ,S. (2015).An Introduction into Virtual Reality Environments, Uppsala University

[23] Shannon, Baker.(2016).Making Paradigms Meaning in Mixed Methods Research, Sage Journals

[24] Stenger, M. (2017). 10 Ways Virtual Reality Is Already Being Used in Education. InformED

[25] Technomag. (2017).Veative Bringing Zim Education To Life With VR Technology. www.technomag.co.zw

[26] Terrell, S. R. (2012). Mixed-Methods Research Methodologies. The Qualitative Report, 17(1), 254-280. Retrieved from https://nsuworks.nova.edu/tqr/vol17/iss $1 / 14$

[27] Terry, H. (2018). 12 Principles of Mobile Learning, accessed on 01 September 2019

[28] www.multimediacommunication.com

[29] Yin, R. (2017). Case study research: Design and methods. Thousand Oaks, CA: Sage 